\title{
Comparative Study of Mamdani-type and Sugeno-type Fuzzy Inference Systems for Coupled Water Tank
}

\author{
Halim Mudia \\ Departement of Electrical Engineering, State Islamic University of Sultan Syarif Kasim Riau \\ Email: halim.mudia@uin-suska.ac.id
}

\begin{tabular}{l}
\hline \hline Article Info \\
\hline Article history: \\
Received Feb $19^{\text {th }}, 2020$ \\
Revised Mar $10^{\text {th }}, 2020$ \\
Accepted Mar $29^{\text {th }}, 2020$
\end{tabular}

\section{Keyword:}

Coupled Water Tank

Fuzzy Inference System

Mamdani

Sugeno

\begin{abstract}
The level and flow control in tanks are the heart of all chemical engineering system. The control of liquid level in tanks and flow between tanks is a basic problem in the process industries. Many times the liquids will be processed by chemical or mixing treatment in the tanks, but always the level of fluid in the tanks must be controlled and the flow between tanks must be regulated in presence of non-linearity. Threfore, in this paper will use fuzzy inference systems to control of level 2 are developed using Mamdani-type and Sugeno-type fuzzy models. The outcome obtained by two fuzzy inference systems is evaluated. This paper summarizes the essential variation among the Mamdani-type and Sugeno-type fuzzy inference systems with setpoint of level is 10 centimeter. Matlab fuzzy logic toolbox is used for the simulation of both the models. This also confirms which one is a superior choice of the two fuzzy inference systems to control of level 2 in tank 2. The results show madani-type fuzzy inference system is superior as compared to sugeno-type fuzzy inference system.
\end{abstract}

Copyright (C) 2020 Puzzle Research Data Technology

\author{
Corresponding Author: \\ Halim Mudia \\ Department of Electrical \\ Engineering Faculty of Science \\ and Technology \\ State Islamic University of Sultan Syarif Kasim Riau \\ Soebrantas 155 Pekanbaru - Indonesia \\ Email: halim.mudia@uin-suska.ac.id
}

DOI: http://dx.doi.org/10.24014/ijaidm.v3i1.9309

\section{INTRODUCTION}

Fuzzy logic is a computational standard that is supported on the feelings of a human. Fuzzy logic appears at the globe in indefinite conditions, to a large extent human mind takes in information then responds with exact actions. The importance in fuzzy system is flashed by Seiji Yasunobu and Soji Miyamoto of Hitachi, who offered simulations which established the advantage of fuzzy control systems for the Sendai railway. Their suggestions were accepted, and fuzzy systems were employed to control speed up and braking. In 1987, at some stage in a worldwide get together of fuzzy examiners in Tokyo, Takeshi Yamakawa started the exercise of fuzzy control through a deposit of straightforward devoted fuzzy logic chips in an inverted pendulum test. It is a typical control trouble, in which an automobile attempts to maintain a pole mounted on its apex by an axis vertically by folding backward and forward. Afterward experiments by Yamakawa in which he raised a wine tumbler having water or a live mouse to the apex of the pendulum. The method preserved permanence in both cases. Yamakawa finally went on to systematize his own fuzzy-systems research laboratory to assist utilize his patents in the field. There are several other applications of fuzzy logic. These applications include medical expert systems, hand-printed character recognition, voice recognition, fuzzy automatic transmission system, autofocusing camera, automated space docking system, washing machines [1].

The liquid level control in Coupled Tank System is a classical benchmark control problem. Level control is one of the control system variable which are more important in process industries. The process industries requires liquid to be pumped as well as stored in tanks and then repumped to another tank. Many times the liquids will be processed by chemical or mixing treatment in the tanks, but always the level of fluid in the tanks must be controlled and the flow between tanks must be regulated. The quality of the product of the

Journal homepage: http://ejournal.uin-suska.ac.id/index.php/IJAIDM/index 
mixture depends on the level of the reactants in the mixing tank. Tank level control systems are used frequently in different processes. All of the pharmaceutical industries, petrochemical plants, food industries and nuclear power plants depend upon tank level control systems. It is essential for control system engineers to understand how tank control systems work and how the level control problem is solved. The liquid level system has time varying system parameters and non-linear characteristics in the complex industrial process. Most of the control performances in the actual design are usually defined by steady state error, overshoot, rising time, settling time [2].

Various attempts in controlling liquid level of coupled tank system were proposed. The design of PI controller using Characteristics Ratio Assignment method for linear modelled coupled tank SISO process was proposed by M. Senthilkumar et al [3] and The mathematical modelling and designing of Sliding Mode Control for a liquid level control system when tanks are coupled by using baffles was proposed by Hur Abbas et al [4]. Muhammad Nasiruddin Mahyuddin et al proposed a Direct Model Reference Adaptive Control for Coupled Tank System [5] and Comparison between PI and MRAC on coupled tank system done by M. Saad et al [6].

\section{RESEARCH METHOD}

This research is this paper presents the mathematical modelling of coupled water tank, fuzzy inference system, mamdani-type fuzzy inference system, and sugeno-type fuzzy inference system.

\subsection{Mathematical Modelling Of Coupled Water Tank}

The coupled tank as shown in Figure 1 is a coupled tank for the experimental scale. Consists of two tanks and pumps that function to pump water vertically [7]:

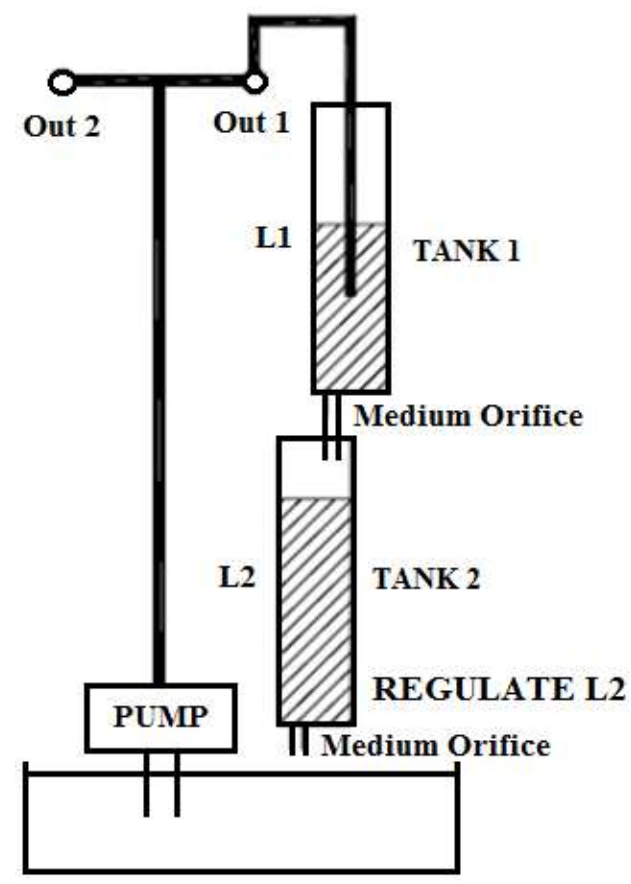

Figure 1. Coupled Water Tank

The flow into the tank 1 is:

$$
F_{1 i n}=K_{m} V_{p} \mathrm{~cm}^{3} / \mathrm{sec}
$$

where $K_{m}$ is the constant pump and $V_{p}$ is the voltage applied to the pump. The outflow velocity is given by the Bernauli equation for small orifices:

$$
V_{o}=\sqrt{2 g L_{1}} \mathrm{~cm} / \mathrm{sec}
$$


where $g$ is the gravitational acceleration in $\mathrm{cm} / \mathrm{sec}^{2}$ and $L_{1}$ is the high of the water level in the tank 1 in $\mathrm{cm}$. The outflow rate is:

$$
F_{1 \text { in- }} F_{1 o u t}=K_{m} V_{p}-\alpha_{1} \sqrt{2 g L_{1}} \mathrm{~cm}^{3} / \mathrm{sec}
$$

Then the change in level of tank 1 is then given, where $A_{1}$ is the diameter of the tank 1 :

$$
\dot{L}_{1}=-\frac{\alpha_{1}}{A_{1}} \sqrt{\frac{g}{2 L_{10}}} L_{1}+\frac{K_{m}}{A_{1}} V_{p}
$$

The equation of tank 2 for inflows and outflows is:

$$
\begin{aligned}
& F_{1 \text { in }}=\alpha_{1} \sqrt{2 g L_{1}} \mathrm{~cm}^{3} / \mathrm{sec} \\
& F_{2 \text { out }}=\alpha_{2} \sqrt{2 g L_{2}} \mathrm{~cm}^{3} / \mathrm{sec}
\end{aligned}
$$

Then the change in level of tank 2 is then given by:

$$
\dot{L}_{2}=-\frac{\alpha_{2}}{A_{2}} \sqrt{\frac{g}{2 L_{20}}} L_{2}+\frac{\alpha_{1}}{A_{2}} \sqrt{\frac{g}{2 L_{10}}} L_{1}
$$

If $x_{1}=L_{1}$ and $x_{2}=L_{2}$ then equation state of system can write as:

$$
\begin{aligned}
& \dot{x}_{1}=-\frac{\alpha_{1}}{A_{1}} \sqrt{\frac{g}{2 L_{10}}} x_{1}+\frac{K_{m}}{A_{1}} V_{p} \\
& \dot{x}_{2}=-\frac{\alpha_{2}}{A_{2}} \sqrt{\frac{g}{2 L_{20}}} x_{2}+\frac{\alpha_{1}}{A_{2}} \sqrt{\frac{g}{2 L_{10}}} x_{1}
\end{aligned}
$$

and the parameter of equation (8) and (9), can we see in Table 1:

Table 1. Parameter of Coupled Water Tank

\begin{tabular}{cccc}
\hline Parameter & Symbol & Value & Units \\
\hline Diameter of Tank 1 & $\mathrm{A}_{1}$ & 15,5179 & $\mathrm{~cm}^{2}$ \\
Diameter of Tank 2 & $\mathrm{A}_{2}$ & 15,5179 & $\mathrm{~cm}^{2}$ \\
Gravity & $\mathrm{g}$ & 980 & \\
Pump Constant & $\mathrm{Km}$ & 4,6 & $\left(\mathrm{~cm}^{3} / \mathrm{s}\right) /$ Volt \\
Level Water of Tank 1 & $\mathrm{L}_{2}$ & terukur & $\mathrm{cm}$ \\
Level Water of Tank 2 & $\mathrm{L}_{1}$ & terukur & $\mathrm{cm}$ \\
Cross Section Area of Tank 1 & $\alpha_{1}$ & 0,17813919765 & $\mathrm{~cm}$ \\
Cross Section Area of Tank 2 & $\alpha_{2}$ & 0,17813919765 & $\mathrm{~cm}$ \\
Pump Voltage (max) & $\mathrm{Vp}_{\text {m }}$ & 22 & $\mathrm{Volt}$ \\
Tank 1 Work Point & $\mathrm{L}_{10}$ & 15 & $\mathrm{~cm}$ \\
Tank 2 Work Point & $\mathrm{L}_{20}$ & 15 & $\mathrm{~cm}$ \\
\hline
\end{tabular}

\subsection{Design of Fuzzy Inference System to Control Level of Coupled Water Tank}

Fuzzy Logic Controller, briefly called Fuzzy Controller, is to solve the control problems of some objects. These problems cannot be solved by the traditional control methods while can be solved by some experienced operating workers. So Fuzzy Controller is suiTable to imitate the experts' control of some complicated systems which the mathematical models are unknown [8]. In this paper we can explain 2 main parts of this design system to control level of Coupled Water Rank is, where all the design system with setpoint $=10$ centimeter $(\mathrm{cm})$ is: 


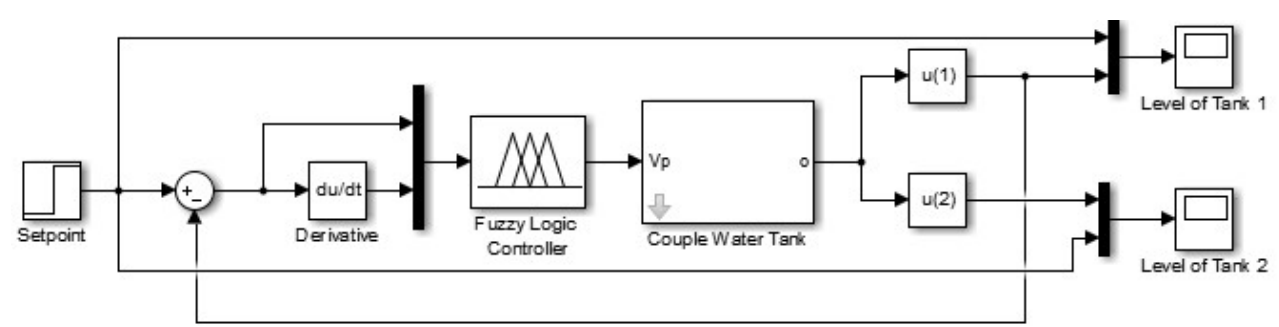

Figure 2. Design of The Coupled Water Tank and Fuzzy in Matlab

and for the Couple Water Tank can we see in Figure 3 and Figure 4:

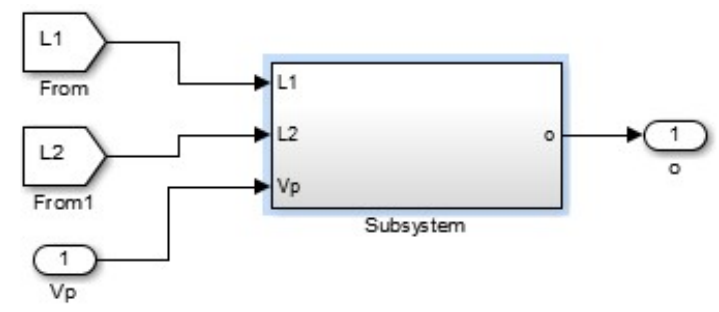

Figure 3. Design of Subsystem of The Coupled Water Tank in Matlab

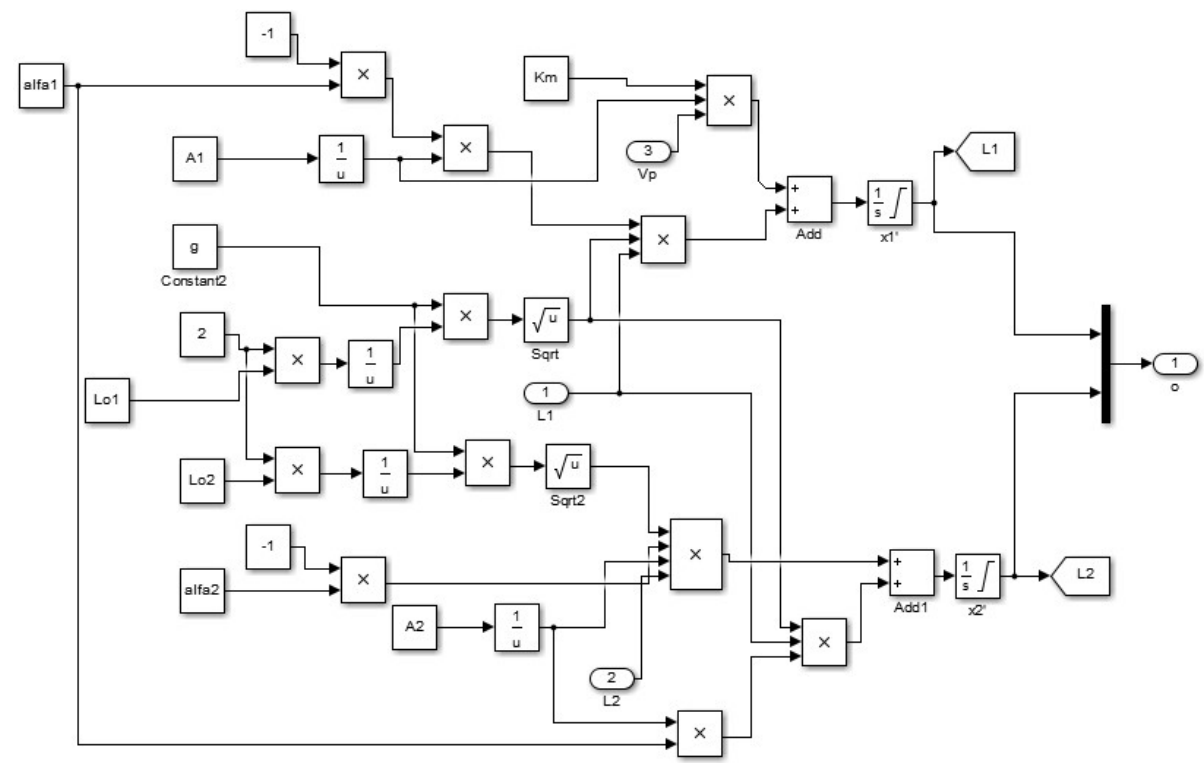

Figure 4. Design Inner of Subsystem of The Coupled Water Tank in Matlab

and while for design control fuzzy:

a. Design of Mamdani-type Fuzzy Inference System to Control Level of Coupled Water Tank

For design of Mamdani-type fuzzy Inference System to control level of Coupled Water Tank is required 2 input (error: e and derivative error: de) and 1 ouput (control signal): 


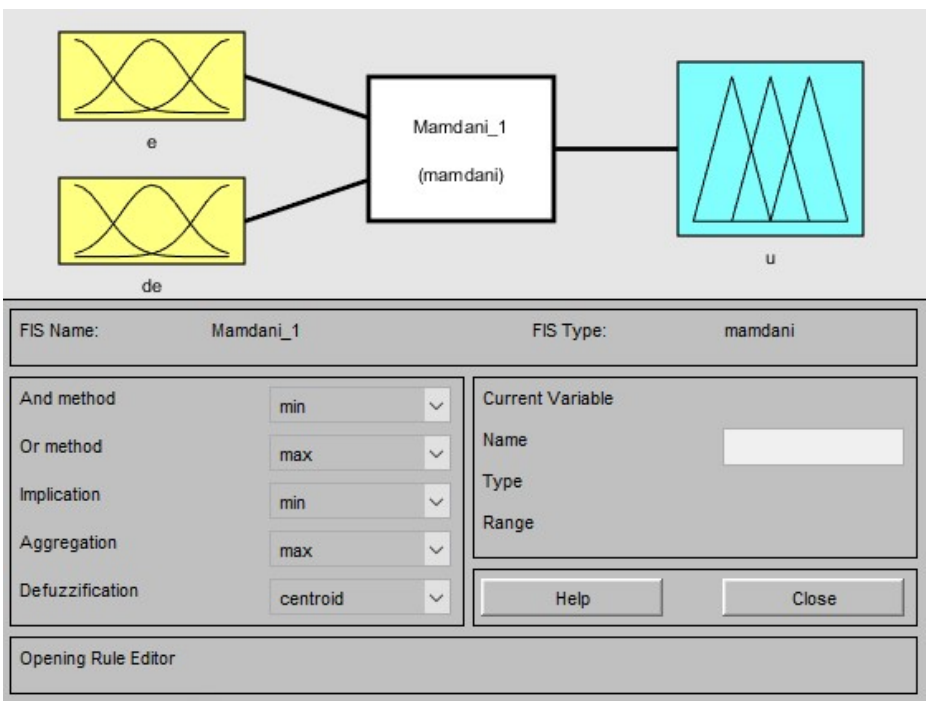

Figure 5. Design of Mamdani-type Fuzzy Inference System

where range of them we can predict by our experience with this system, so we can choose range of error (e), derivative (de), and control signal (de) is:

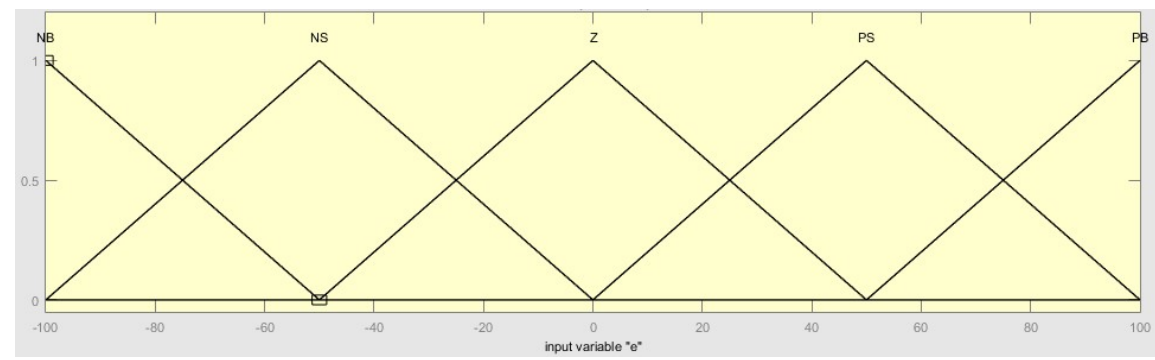

Figure 6. Membership Functions of Error (e)

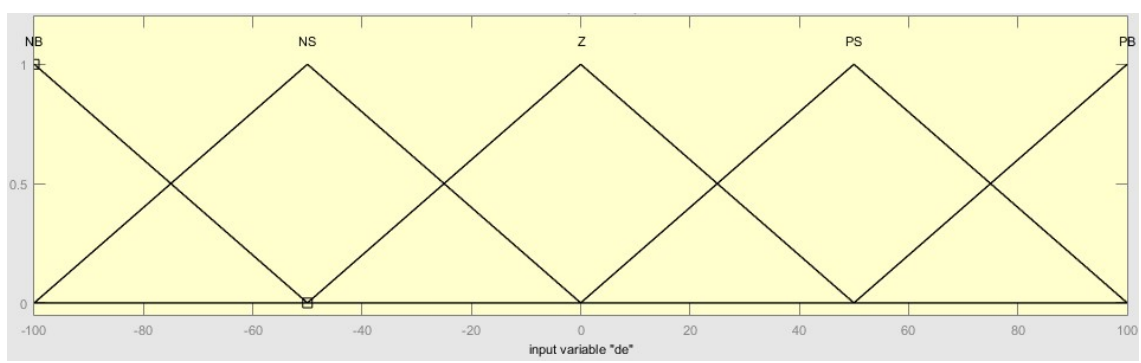

Figure 7. Membership Functions of Derivative (de)

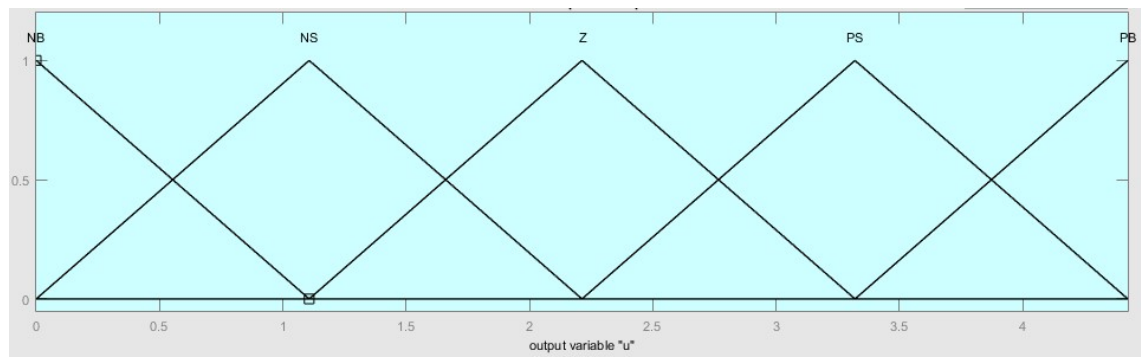

Figure 8. Membership Functions of Control Signal (u) 
and for rule base we use Table of Mack Vicar Whelan:

\begin{tabular}{|c|c|c|c|c|c|c|}
\hline \multirow{2}{*}{$\begin{array}{c}\text { Control Signal } \\
\text { (u) }\end{array}$} & \multicolumn{5}{|c|}{ Derivative (de) } \\
\cline { 2 - 7 } & NB & NS & Z & PS & PB \\
\hline \multirow{4}{*}{$\begin{array}{c}\text { Error } \\
\text { (e) }\end{array}$} & NB & PB & PB & PB & PS & Z \\
\cline { 2 - 7 } & NS & PB & PB & PS & Z & NS \\
\cline { 2 - 7 } & Z & PB & PS & Z & NS & NB \\
\cline { 2 - 7 } & PS & PS & Z & NS & NB & NB \\
\cline { 2 - 7 } & PB & Z & NS & NB & NB & NB \\
\hline
\end{tabular}

Figure 9. Membership Functions of Control Signal (u)

\section{b. Design of Sugeno-type Fuzzy Inference System to Control Level of Coupled Water Tank}

For design of Sugeno-type fuzzy Inference System to control level of Coupled Water Tank is required 2 input (error: e and derivative error: de) and 1 ouput (control signal):

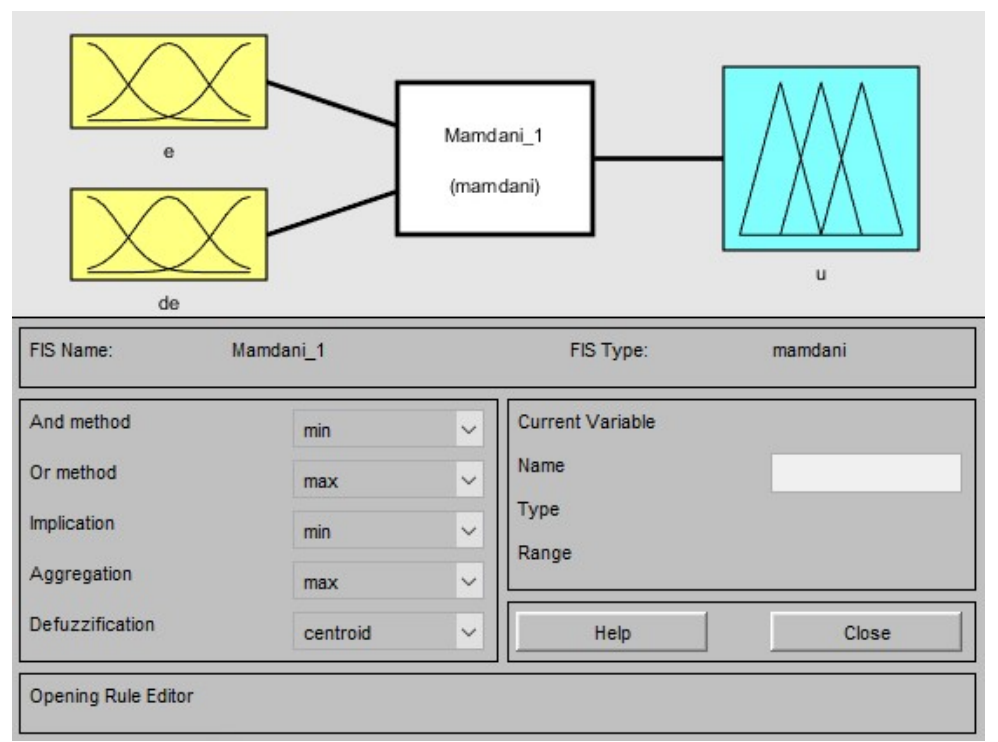

Figure 10. Design of Mamdani-type Fuzzy Inference System

where range of them we can predict by our experience with this system, so we can choose range of error (e), derivative (de), and control signal (de) is:

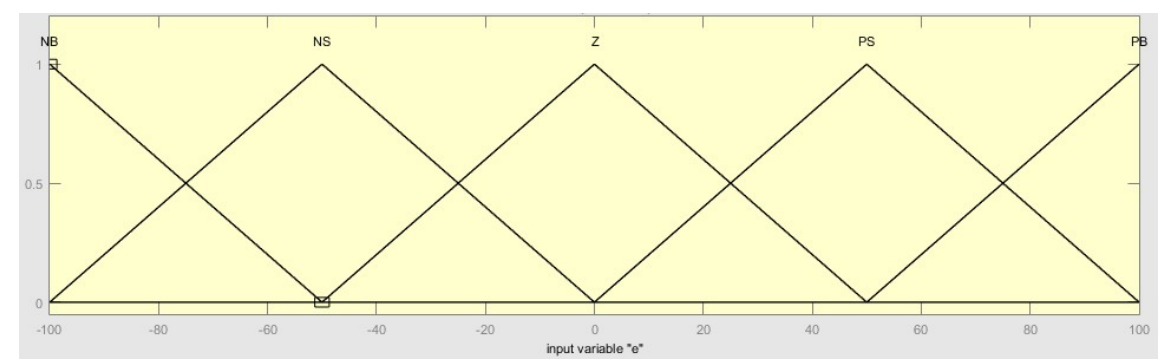

Figure 11. Membership Functions of Error (e) 


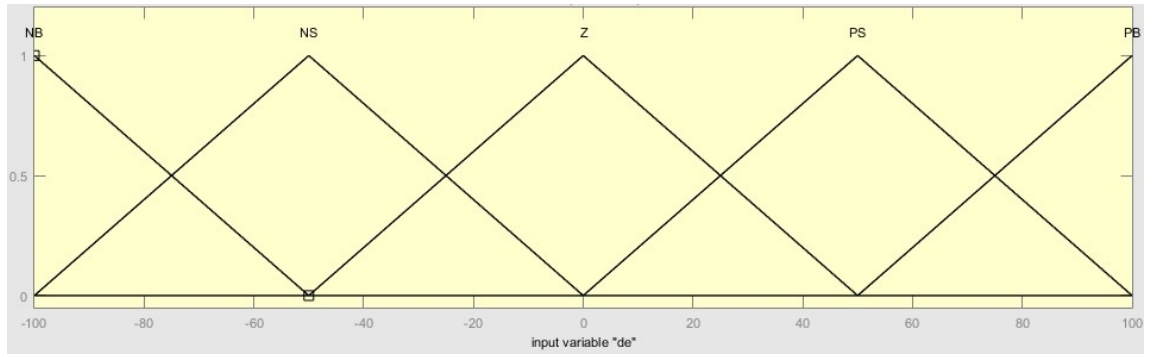

Figure 12. Membership Functions of Derivative (de)

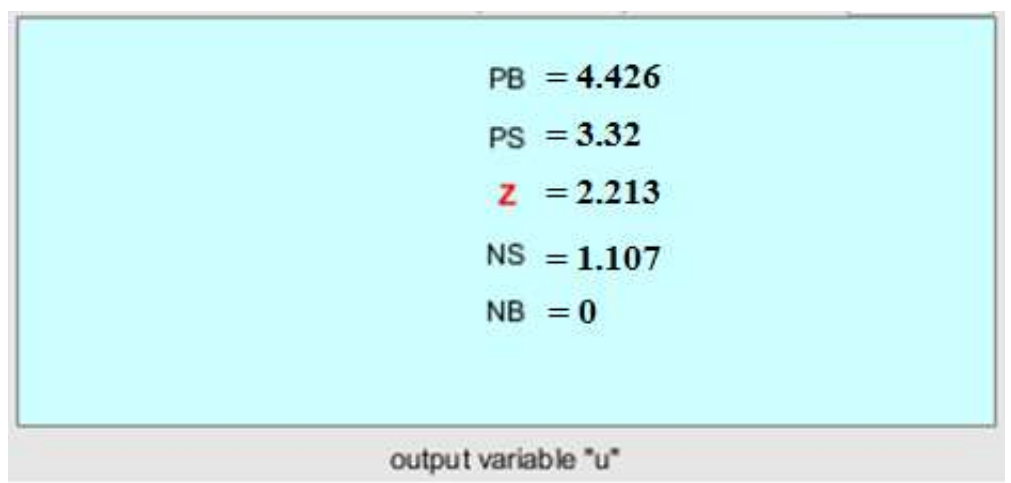

Figure 13. Membership Functions of Control Signal (u)

and for rule base we use Table of Mack Vicar Whelan like in Figure 9.

\section{RESULT AND ANALISYS}

In the course of testing the performance of the system we can define by steady state error, overshoots, rising time, and settling time:

\subsection{Design of Mamdani-type Fuzzy Inference System to Control Level of Coupled Water Tank}

The response output system in Figure 13, we can analisys for steady state error is $0 \mathrm{~cm}$, overshoot is $0 \%$, rising time is 63 seconds, and settling time is 69 seconds.

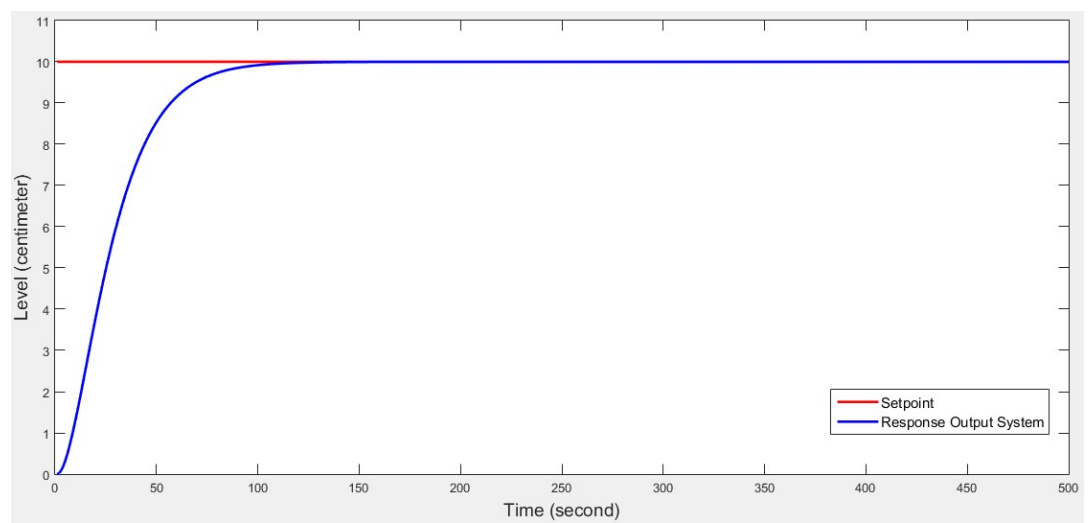

Figure 14. Response Output System for Level 2 in Tank 2 with Mamdani-type Fuzzy

\subsection{Design of Sugeno-type Fuzzy Inference System to Control Level of Coupled Water Tank}

The response output system in Figure 15, we can analisys for steady state error is $0 \mathrm{~cm}$, overshoot is $0 \%$, rising time is 64 seconds, and settling time is 70 seconds. 


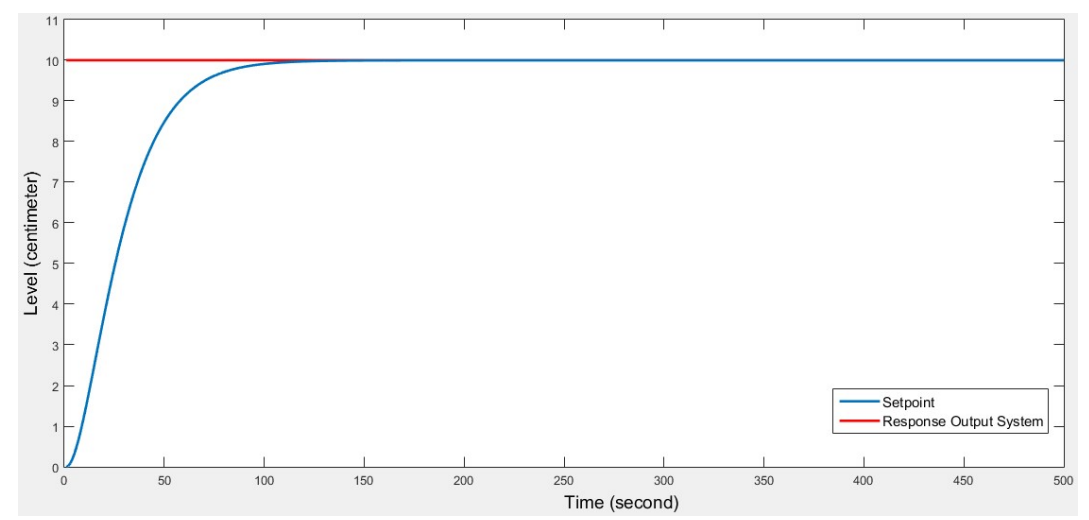

Figure 15. Response Output System for Level 2 in Tank 2 with Sugeno-type Fuzzy

\section{CONCLUSION}

It may be concluded from this paper, the outcome achieved from madani-type fuzzy inference system is more better as compared to sugeno-type fuzzy inference system, it can we see in rising time with madanitype fuzzy inference system is 63 seconds and settling time is 69 second, while rising time with sugeno-type fuzzy inference system is 64 seconds and settling time is 70 seconds.

\section{REFERENCES}

[1] Abraham L, Senthilkumar, Selvakumar. Design of PI Controller Using Characteristics Ratio Assignment Method for Coupled Tank SISO Process. International Journal of Computer Application. 2011; 25(9): 49-53.

[2] Hur A, Sajjad A, Shahid Q. Sliding Mode Control Of Coupled Tank Liquid Level Control System. IEEE 10th International Conference on Frontires of Information Technology. Islamabad. 2012; 325-330.

[3] Jiffy A. J, Jaffar, Riya. M. F. Modelling and Control of Coupled Tank Liquid Level System Using Backstepping Method. International Journal of Engineering Research \& Technology (IJERT). 2015; 4(6): 667-671.

[4] Jimmy S. Comparative Study of Mamdani-Type and SugenoType Fuzzy Inference Systems for Diagnosis of Diabetes. International Conference on Advances in Computer Engineering and Applications (ICACEA). Ghaziabad. 2015; 517-522.

[5] Mahyuddi N. M, Arshad R. M, Zaharuddin M. Simulation of Direct Model Reference Adaptive Control on a Coupled Tank System Using Non-linear Pant Model. International Conference on Control Instrumentation and Mechatronics Engineering. Johor. 2007; 569-576.

[6] Saad M, Albagul A, Abueejela Y. Performance Comparison between PI and MRAC for Coupled Tank Rystem. Journal of Automation and control Engineering. 2014; 2 (3): 316-321.

[7] Wei J. The Application of the Fuzzy Theory in the Design of Intelligent Building Control of Water Tank. Journal of Software. 2011; 6(6): 1082-53.

[8] Yuan C, Wei H. C, Yan Y, Min W. Dynamic Modeling and Model Mismatch of Coupled Water Tanks System. Proceedings of the 32nd Chinese Control Conference. Xian. 2013.

\section{BIBLIOGRAPHY OF AUTHORS}

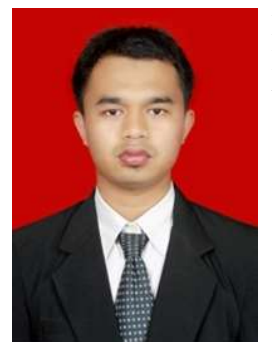

Halim Mudia was raised and borned in Pakan Kamis, West Sumatera. He is a lecturer in the Electrical Engineering, State Islamic University of Sultan Syarif Kasim Riau. Completing a Masters degree at the Sepuluh Nopember Institute of Technology (ITS) in 2015. 